\title{
Design of Triple-Stage Cascoded LNA Amplifiers using Inductive Drain Feedback (IDF) Technique for WiMAX Application
}

\author{
Kamil PONGOT ${ }^{1.2}$, Abdul Rani OTHMAN ${ }^{2}$, Zahriladha ZAKARIA ${ }^{2}$, Mohamad Kadim \\ SUAIDI $^{2}$, Abdul Hamid HAMIDON ${ }^{2}$, Azman AHMAD ${ }^{2}$, and Mohamad Tarmizy AHMAD ${ }^{2}$ \\ ${ }^{1}$ Bahagian Sumber Manusia, Majlis Amanah Rakyat (MARA) \\ Tingkat 17 \& 18 Ibu Pejabat MARA, Jalan Raja Laut, 50609 Kuala Lumpur, Malaysia \\ ${ }^{2}$ Centre of Telecommunication and Innovation (CETRI), Faculty of Electronics and Computer Engineering \\ Universiti Teknikal Malaysia Melaka (UTeM), Hang Tuah Jaya \\ 76100, Durian Tunggal, Melaka, Malaysia. \\ kamilpongot@yahoo.com.sg,rani@utem.edu.my,zahriladha@utem.edu.my, \\ kadim@utem.edu.my, hamid@utem.edu.my, azmanahmad888@gmail.com, \\ tarmizy@gmail.com
}

\begin{abstract}
This paper presents the design of triple stages cascoded low noise amplifier using an inductive drain feedback (IDF) technique which operates at frequency $5.8 \mathrm{GHz}$ for WiMAX application. The triple stages cascoded LNA was designed using the inductive drain feedback, inductive generation to the source, and the T-network at the input and output terminal as a matching technique. This LNA produced a gain $\left(\mathrm{S}_{21}\right)$ of $79.16 \mathrm{~dB}$ and the noise figure $(\mathrm{NF})$ of $0.71 \mathrm{~dB}$. The output reflection $\left(\mathrm{S}_{22}\right)$, input reflection $\left(\mathrm{S}_{11}\right)$ and return loss $\left(\mathrm{S}_{12}\right)$ are $-12.56,-11.96 \mathrm{~dB}$ and $-100.22 \mathrm{~dB}$ respectively. The measured $3 \mathrm{~dB}$ bandwidth of $1.76 \mathrm{GHz}$ has been achieved. The input sensitivity is $92 \mathrm{dBm}$ exceeded the standards required by the IEEE 802.16. The amplifier it is implemented using superHEMT FHX76LP transistor devices. The designed circuit is simulated with Ansoft Designer SV.
\end{abstract}

Keywords:RF front-end; IEEE 802.16; Cascoded LNA; Inductivedrain feedback

\section{Introduction}

Heightened demand for broadband services by consumers at this point has become a growing trend in every country in this world. As it is known that the era before the advent of broadband, many countries using digital lines (DSL), fiber optic, cable modem and Ethernet as a resolution to provide high-speed broadband [1]. In reality, it is not a good technological solution for most telecommunications companies forced to suffer the high cost and difficult to maintenance on the wired net, especially in rural and distant regions. Therefore, the technology of broadband wireless access has been introduced where it is more flexible, more efficient and more affordable to users. Broadband wireless access technology the most popular at the moment is WiMAX. Using IEE 802.16 standard, which enables users to access wireless

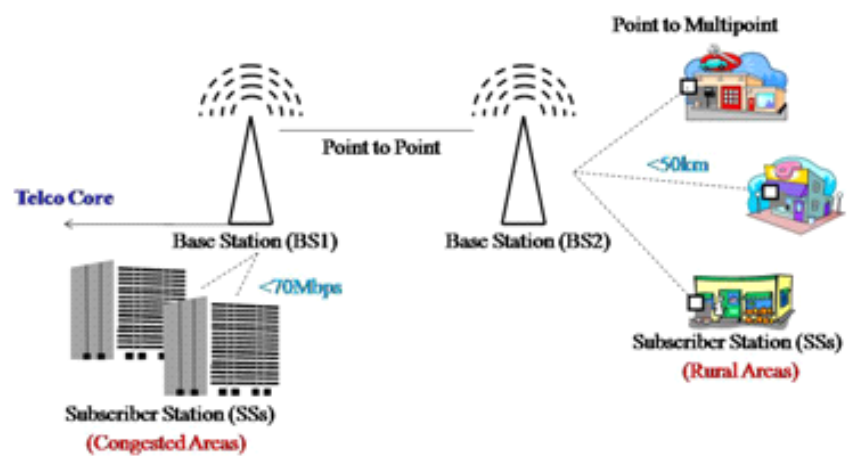

Figure 1. WiMAX Deployment Scenarios [4]

Received: April $17^{\text {th }}, 2014$. Accepted: April $9^{\text {th }}, 2015$ 
rates $(70 \mathrm{Mbps})$ compared to $802.11 \mathrm{a}$ to provide data rates only $54 \mathrm{Mbps}$ up to several hundred meters, EDGE with only transfer data rates until $384 \mathrm{kbps}$ to a few kilometers and CDMA2000 broadband anywhere, anytime and on any device that is installed with wireless devices [2]. WiMAX technology has more capacity (user), large area coverage $(50 \mathrm{~km})$ and delivers high to 2 Mbps for a few kilometersWiMAX technology has advantages in terms of high mobility performance and is one of the most user-friendly technology [3].WiMAX deployment scenarios are shown in Figure 1.

The frequency spectrum of mobile WiMAX technology in NLOS applications is around 2 $6 \mathrm{GHz}$, where the $2.3 \mathrm{GHz}, 2.5 \mathrm{GHz}$ and $3.5 \mathrm{GHz}$ are dedicated for licensed spectrum while the $3.65 \mathrm{GHz}$ and $5.8 \mathrm{GHz}$ are dedicated for unlicensed spectrum. In this research the preferred concentration of the unlicensed spectrum at $5.8 \mathrm{GHz}$ frequency. In this research the preferred concentration of the unlicensed spectrum at $5.8 \mathrm{GHz}$ frequency. In the WiMAX receiver configureuration, RF front-end is designed with extensive bandwidth, low interference, high gain and sensitivity performance ensure a reliable receiving performance. The main component in the RF front-end is a low-noise amplifier (LNA). The low noise amplifier in the first stage will dominate the noise, gain, and the sensitivity performance of the RF front-end receiver. Therefore, to guarantee the implementation of the best front-back RF, LNA should be designed to optimize at the input or output impedance matching, high gain, low noise, and unconditional stability in a predetermined band.

Low noise amplifier (LNA) is the core blocks in the RF front-end receiver because it will strengthen and reduce the noise figureure of the received signal from the antenna to the signal level that can be accepted by the receiver system. Selection, the correct LNA technology and timely in RF front-end receiver, is a way to get the cost-efficient and manageable. In selecting LNA technology, there are several factors that to be considered such as the selected device capabilities, the number of signal content to be integrated and the application performance requirements.

Typically, most of the researchers are focusing on SiGe (BiCMOS) or CMOS transistor in designing LNAs. However, most of the commercial LNAs are designed using the GaAsPHEMT. The use of GaAs-PHEMT devices in commercial LNAs are due to the noise figureure produced by these devices that can be reduced up to $0.5 \mathrm{~dB}$. Thus, designers must find the technology that is suitable for applications to be developed to ensure a balance between the technology performances that can be obtained. However, this technology is still uncertain due to the difference in terms of architecture, specification and circuit designers themselves [5]. In this research, LNA for WiMAX applications designed using PHEMT technology and focus on the new structure. Eudyna Devices Inc FHX76LP that was found to have excellent stability at the required frequency range 5.3-6.2 GHz. This is the transistor PHEMT and provides a high gain $18 \mathrm{~dB}$ at $6 \mathrm{GHz}$ and a low noise figureure $0.4 \mathrm{~dB}$ at $12 \mathrm{GHz}$. Transistor that uses low current of $10 \mathrm{~mA}$ with the drain-source voltage of 2 volts. Therefore, FHX76LP has been selected to design the LNA.

In this research, we proposed triple stages cascaded LNA using topologies inductive drain feedback to the drain, inductive source degenerated and the T matching network at the input and output ports. This topology is designed to obtain more than $70 \mathrm{~dB}$ gain, and noise figureure is less than $3 \mathrm{~dB}$ as well as maintaining in more than $1 \mathrm{GHz}$ bandwidth. The proposed architecture for the configureuration RF front-end receiver a WiMAX application at $5.8 \mathrm{GHz}$ as shown in Figure 2. Development of LNA in the front-end receiver is the primary focus of this research.

In this configuration, it consists of triple stages cascoded LNA using the inductive drain feedback combined with source inductive degeneration, inductive RF choke placed between the two cascoded LNA amplifier and the input and output ports using the T-matching network. Adding the inductive drain feedback at the cascoded topology has provided high gain, wider bandwidth, better stability, higher reverse isolation and provide the best matching at the input or output terminal, that it also helps in increasing the bandwidth. While the addition of an inductive source generation at cascoded LNA topology enhances the bandwidth, stability and 
improve the input-output matching capabilities. The use of T-matching on this configuration also has helped reduce the reverse isolation and noise figure.

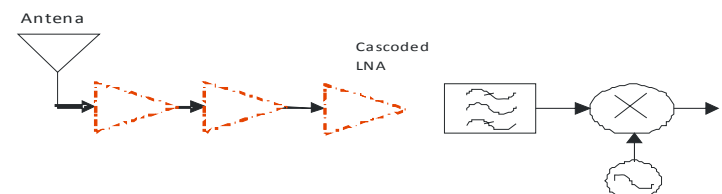

Figure 2. RF front-end receiver architecture using a triple stagecascodedLNA configuration

\section{LNA Theory}

LNA is used to amplify the signal received from the transmitter to a level that can be accepted and only a slight increase in noise. It is the most critical part of the RF front-end receiver, especially if it is referred to in receiver performance. A variety of LNA circuit designs using different configuration was proposed by the researcher prior to use on the application of wireless broadband. The selection of the right combination of design LNA circuit necessary to obtain optimal designs. In this section, the design and optimization techniques for LNA will be reviewed and clarified.

\section{A. Common Source (CS), Common Gate(CG) and Cascode Configuration}

A designer who specializes LNA will choose the correct circuit for use in a particular application. The selection of the proper circuit for LNA design is very important to allow players of telecommunication systems to provide coverage in the desired area. In addition, the circuit can be designed only to meet some characteristics of LNA while others can be ignored. This is important for designers to reduce the effects of environmental variables as well as getting the best trade-off between characteristics to optimize receiver sensitivity, selectivity and maintain the integrity of the data.

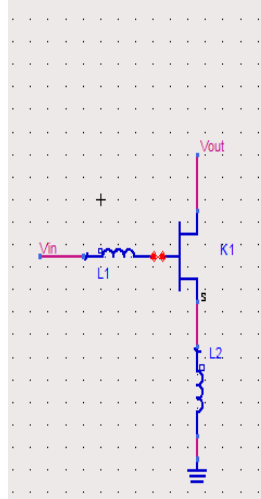

(a)

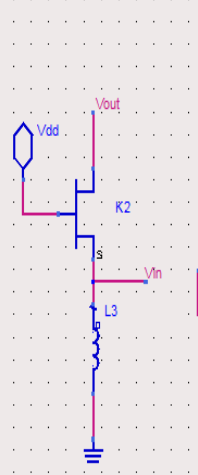

(b)

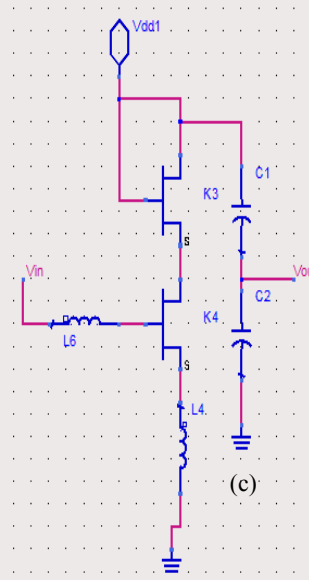

Figure 3. (a) Common-source (CS), (b) Common-gate (CG) and (c) Cascode Topology

Figure 3 shows Common-source (CS), Common-gate (CG) and Cascode topology are commonly used in LNA design. The use of (CS) topology in LNA circuit will increase the gain and can produce good noise performance [6]. When an inductor is placed on the source of a (CS) stage, then the inductive source will be degenerated. The inductively degenerated (CS) LNA is widely used due to the superior noise performance, wider bandwidth with large power consumption [7], but it is poor in terms of reverse isolation. Upon the occurrence of the technological revolution of the last which requires a larger wideband operation to enable various advanced applications used by consumers using the (CS) topology, the LC ladder 
technique used at the input LNA to provide the required input impedance over the bandwidth used [8]. For (CG) LNA topology usually can achieve wideband input impedance matching and the best input-output isolation. However, it has a high noise figure [9]. (CG) topology can also lower power consumption, robust again parasitic and stabilize the LNA circuit [6]. To overcome the noise performance when using (CG) LNA, the use of capacitive cross-coupling technique was introduced to reduce the noise generated at the common-gate transistor output [10]. This method can overcome the problem of weak noise performance of the LNA. Cascode topology is a common method used to design the LNA. Cascoded topology more popular and often used by designers LNA due to this technique can produce higher gain, high reverse isolation and low power consumption [11]. The cascode LNA with inductive source degeneration shown in Figure 3 (c) has been used extensively and arguably the best topology because it is easier to achieve input matching for higher gain and noise figure compared to using other methods topology. The inhibition of the parasitic capacitances of the input transistor also improves the high-frequency performance of the amplifier. In addition, a combined two-transistors (FETS) in cascode topology increases the bandwidth of the amplifier and reduce the impression of Miller [12]. The cascoded LNA is also suitable for narrowband applications as there is in (CS) topology. However, with the improvement of this technique by using the feedback method allows cascaded stage is used in multiband or wideband application [13]. There are also other methods used to obtain the wideband application in cascaded configuration with the addition of the LC matching network at the input [8]. Table 1 shows the comparison in general based on the most relevant considerations in the design of LNA topology.

Table 1. Comparison between Three LNA Topology

\begin{tabular}{|l|c|c|c|}
\hline \multicolumn{1}{|c|}{ Characteristic } & Cascoded & Common-source & Common-gate \\
\hline Gain & Superior & Average & Inferior \\
\hline Stability & Higher & Need compensation & Higher \\
\hline Noise Figure & $\begin{array}{c}\text { Slightly higher than } \\
\text { CS }\end{array}$ & Inferior & $\begin{array}{c}\text { Increased when } \\
\text { frequency rise }\end{array}$ \\
\hline Bandwidth & Broad & Narrow & $\begin{array}{c}\text { Slightly broad than } \\
\text { CS }\end{array}$ \\
\hline $\begin{array}{l}\text { Sensitivity, Power } \\
\text { supply, Component } \\
\text { Tolerance }\end{array}$ & Lesser & Greater & Lesser \\
\hline Reverse Isolation & High & Low & High \\
\hline Linearity & Potentially highest & Average & High \\
\hline
\end{tabular}

From Table 1 we can deduce, cascoded amplifier is the best among the three topologies which was designed by the researcher earlier due to meet all the requirements and the most versatile of all the important characteristics for LNA design. Cascoded topology also provides a more stable gain over a wide bandwidth with little trade-offs in noise figure performance and design complexity. (CS) topology can produce the best in lower noise figure. It also has a greater advantage in sensitivity to bias, component tolerances, and temperature. The (CG) topology also has low noise figure at low frequencies but will increase rapidly with the higher frequency signals. To improve the noise figure, gain and stability at high frequencies due to the high drain-source capacitance in common-gate implementation requires the use of inductive feedback in the circuit.

\section{B. LNA Characteristic}

\section{B.1. Noise Figure}

Noise optimization is the most critical step and should be given serious consideration in the design of LNA amplifiers. However, it can be simplified when LNA amplifier designers use 
the circles of the constant noise figure and constant gain circles to select usable trade-off between noise figure and gain. In general noise figure of 2-port transistor has a minimum value of the specified admittance is given by the equation (1), [14]:

$$
F=F_{\min }+\frac{R_{N}}{G_{S}}\left|Y_{S}-Y_{\text {opt }}\right|^{2}
$$

Where

$Y_{\mathrm{s}}=\mathrm{G}_{\mathrm{s}}+\mathrm{jB}_{\mathrm{s}}$ is the source admittance presented to the transistor.

$\mathrm{Y}_{\mathrm{opt}}=\mathrm{G}_{\mathrm{opt}}+\mathrm{jB}_{\mathrm{opt}}$ is the optimum source admittance.

$\mathrm{R}_{N}$ is the equivalent noise resistance of the transistor.

$\mathrm{G}_{S}$ is the real part of the source admittance

$R_{N}$ to indicate when the condition of $Y_{S} \neq Y_{\text {opt }}$ happen will cause a sudden increase in noise figure. Usually at the same smith chart would plot stability circles, gain circles, noise circles, and input impedance. $\mathrm{Y}_{\mathrm{S}}$ is usually chosen in between the points as a compromise between noise and gain. However, as Figure 4, $Y_{\text {opt }}$ and $Y_{\text {in }}$ can be changed and move around when there is a change in the size of transistors and add source inductance. Therefore, the inductive degeneration can be used in conjunction with transistor sizing will cause $\mathrm{Y}_{\mathrm{opt}}$ and $\mathrm{Yin}$ move closer together, allowing it to meet the low noise figure, high gain and excellent match input amplifier designed [15]. For low noise transistors, manufacturers usually provide $\mathrm{F}_{\min }, \mathrm{RN}$ and $\mathrm{Y}_{\mathrm{opt}}$ by frequencies. $\mathrm{N}$ defined by the formula for desired noise figure, shown in equation (2):

$$
N=\frac{\left|\Gamma_{s}-\Gamma_{o p t}\right|^{2}}{1-\left|\Gamma_{S}\right|^{2}}=\frac{F-F_{\min }}{4 R_{N} / Z_{0}}\left|1+\Gamma_{\text {opt }}\right|^{2}
$$

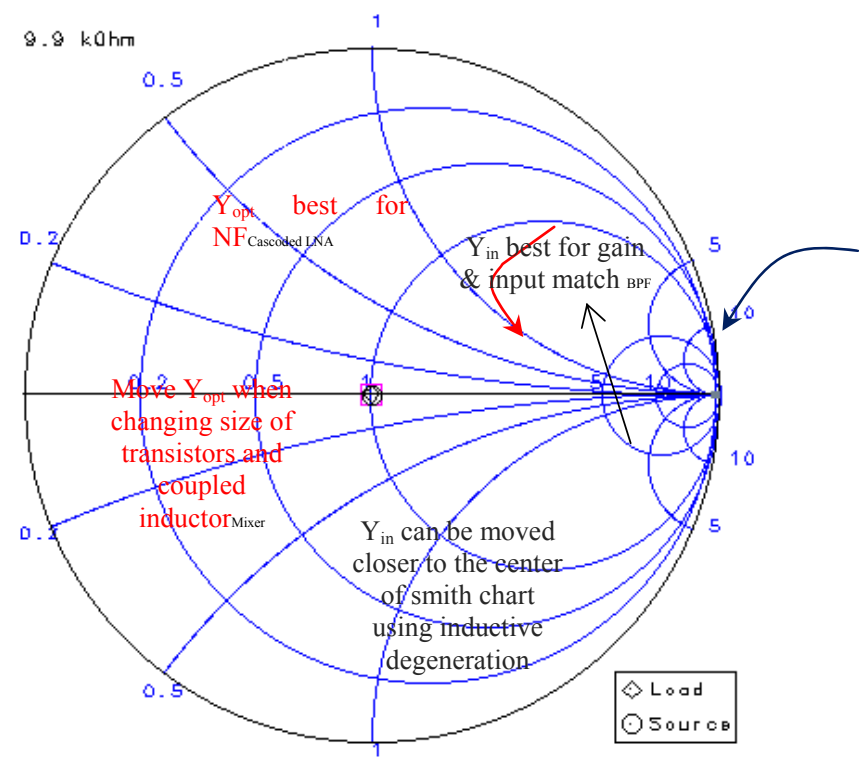

Figure 4. Optimize $\Gamma \mathrm{s}$ for a LNA using inductive degeneration and transistor design

\section{B.2. Stability and Power Gain}

Stability is one of the important characteristics in designing LNA amplifiers. Determination of stability is essential to avoid oscillation occurs at the operating frequency. The oscillation is 
possible if either input or output port impedance has produced a negative real part. This would imply that $\Gamma_{\text {in }}>1$ or $\Gamma_{\text {out }}>1$. This because $\Gamma_{\text {in }}$ and $\Gamma$ out depend on the source and the load matching network. However, the stability of the amplifier depends on $\Gamma_{\mathrm{s}}$ and $\Gamma_{\mathrm{L}}$ as presented as matching network.If low noise amplifiers is not stable, it would become useless since major properties including bandwidth, gain, noise, linearity, DC power consumption and impedance matching can be significantly degraded. For this design, there is a good stability (unconditionally stable) by employing the signal flow theory and S-parameter [15]. Alternatively, the amplifier will be unconditionally stable, when the stability factor $(\mathrm{K})$ and delta factor $(\Delta)$ following necessary and sufficient conditions are met:

$$
K=\frac{1-\left|S_{11}\right|^{2}-\left|S_{22}\right|^{2}+|\Delta|^{2}}{2\left|S_{12} S_{21}\right|}>1
$$

and

$$
|\Delta|=\left|S_{11} S_{22}-S_{12} S_{21}\right|<1
$$

$(\mathrm{K}>1)$ and $(|\Delta|<1)$ is condition requirement for unconditional stability.

The Power Gain of 2-port networks with circuit impedance or load impedance of the power amplifier are represented with scattering coefficient classified into Available Power Gain, Power Transducer Gain and Operating Power Gain [16].

Operating power gain $\left(G_{P}\right)$, is the ratio between the power delivered to the load $\left(P_{L}\right)$ and the power input $\left(\mathrm{P}_{\mathrm{in}}\right)$ to the network. The Operating Power Gain can be specified as an equation (5), [14] :

$$
G_{P}==\frac{P_{L}}{P_{i n}}=\frac{\left|S_{21}\right|^{2}\left(1-\left|\Gamma_{L}\right|^{2}\right)}{\left(1-\left|\Gamma_{i n}\right|^{2}\right) 1-\left.S_{22} \Gamma_{L}\right|^{2}}
$$

Available power gain $\left(\mathrm{G}_{\mathrm{A}}\right)$ is the ratio between the power available from the network $\left(\mathrm{P}_{\mathrm{avn}}\right)$ and the power available from the source $\left(\mathrm{P}_{\mathrm{avs}}\right)$ as shown in equation $(6),[14]$ :

$$
G_{A}=\frac{P_{a v n}}{P_{a v s}}=\frac{1-\left|\Gamma_{S}\right|^{2}}{\left|1-S_{11} \Gamma_{S}\right|^{2}}\left|S_{21}\right|^{2} \frac{1}{\left|1-S_{22} \Gamma_{L}\right|^{2}}
$$

Transducer power gain $\left(\mathrm{G}_{T}\right)$ is the ratio between the power delivered to the load $\left(\mathrm{P}_{\mathrm{L}}\right)$ and the power available from the source $\left(\mathrm{P}_{\text {in }}\right)$ as shown in equation $(7),[14]$ :

$$
G_{T}=\frac{P_{L}}{P_{\text {in }}}=\frac{\left|S_{21}\right|^{2}\left(1-\left|\Gamma_{S}\right|^{2}\right)\left(1-\left|\Gamma_{L}\right|^{2}\right)}{\left|\left(1-S_{11} \Gamma_{S}\right)\left(1-S_{22} \Gamma_{L}\right)-\left(S_{12} S_{21} \Gamma_{S} \Gamma_{L}\right)\right|^{2}}
$$

\section{Design of Tripple Stage Cascoded Using Inductive Drain Feedback (IDF) Technique}

In an effort to produce a low noise amplifier with low noise figure, wide bandwidth, high gain, input and output matching circuits can reduce reflections unwanted signals and unconditional stability, we suggest the new configuration using triple stage cascoded LNA using inductive feedback to drain FET. 
The proposed configuration diagram triple stage cascoded LNA is shown in Figure 5.

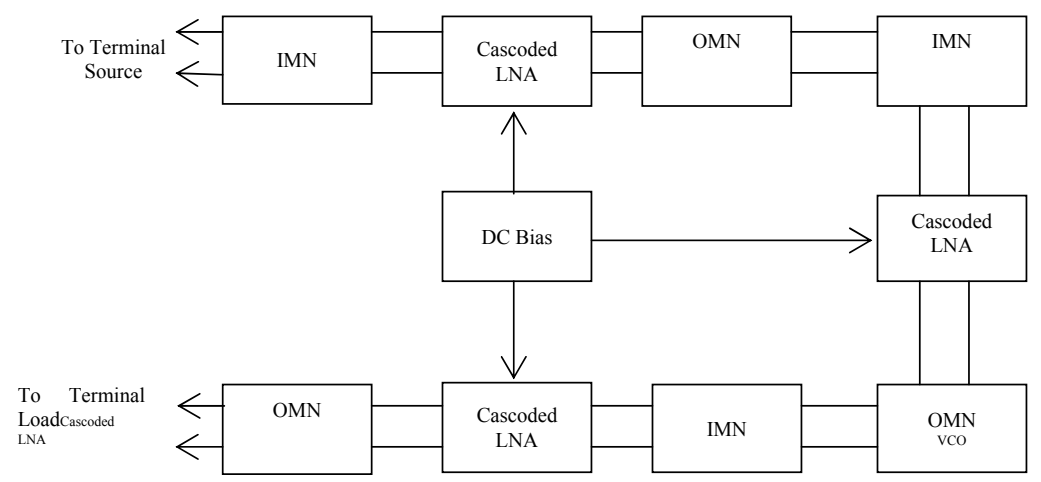

Figure 5. Configuration diagram Triple stage LNA cascoded LNA

The targeted S-parameter specification for the triple stage LNA cascoded LNA amplifier is shown in Table 2.

Table 2. Targeted S-Parameters for a triple stage cascoded LNA amplifier

\begin{tabular}{lc}
\hline \multicolumn{1}{c}{ S- parameter } & $\begin{array}{c}\text { Triple stage LNA } \\
\text { cascoded LNA }\end{array}$ \\
\hline Input reflection $\mathrm{S}_{11}(\mathrm{~dB})$ & $<-10 \mathrm{~dB}$ \\
\hline Return Loss $\mathrm{S}_{12}(\mathrm{~dB})$ & $<-10 \mathrm{~dB}$ \\
\hline $\begin{array}{l}\text { Forward Transfer } \\
(\mathrm{dB})\end{array}$ & $\mathrm{S}_{21}$ \\
\hline $\begin{array}{l}\text { Output Reflection loss } \\
\mathrm{S}_{22}(\mathrm{~dB})\end{array}$ & $<-10 \mathrm{~dB}$ \\
\hline Noise Figure $(\mathrm{dB})$ & $<3 \mathrm{~dB}$ \\
\hline Stability $(\mathrm{K})$ & $\mathrm{K}>1$ \\
\hline Bandwidth $(\mathrm{MHz})$ & $>1000$ \\
\hline
\end{tabular}

Design configuration using a triple stage cascoded LNA and construction specifications in accordance with the specifications in Table 2. The circuit designed using PHEMT FHX76LP Transistor. S-parameters for PHEMT is shown in Table 3, where the parameters were obtained at $\mathrm{V}_{\mathrm{DD}}=2 \mathrm{~V}$ and $\mathrm{I}_{\mathrm{DS}}=10 \mathrm{~mA}$ of bias set at PHEMT.

Table 3.S-parameter from Transistor PHEMT FHX76LP datasheet

\begin{tabular}{lcccc}
\hline $\begin{array}{l}\text { Frequency } \\
\text { GHz }\end{array}$ & $\mathrm{S}_{11}$ & $\mathrm{~S}_{12}$ & $\mathrm{~S}_{21}$ & $\mathrm{~S}_{22}$ \\
\hline $5.8 \mathrm{GHz}$ & 0.712 & 0.065 & 8.994 & 0.237 \\
\hline Angle & -86.54 & 33.88 & 178.66 & -10.46 \\
\hline
\end{tabular}




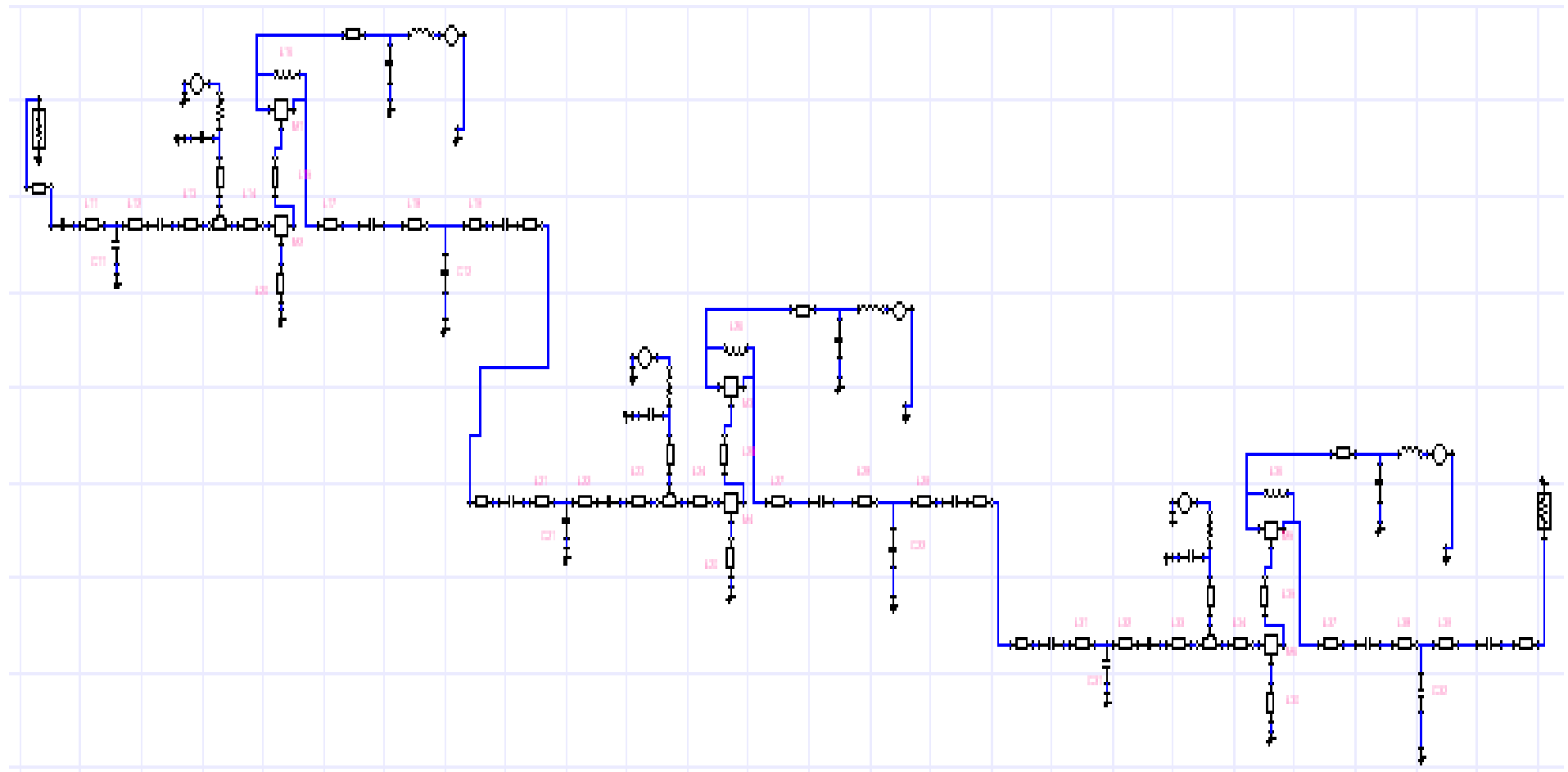

Figure 6. Complete triple stage cascoded LNA using inductive feedback

Low noise amplifiers overall performance can be determined by calculation or simulation using Ansoft 's designer SV software at transducer gain, noise figure and also on the input and output standing wave ratios, VSWR $\mathrm{IN}_{\mathrm{N}}$ and VSWRout. The optimum $\Gamma$ optand $\Gamma \mathrm{L}$ were obtained as $\Gamma$ opt $=21+$ $\mathrm{j} 48.02$ and $\Gamma \mathrm{L}=79.90-\mathrm{j} 7.299$ for cascoded LNA.

Figure 6 shows the complete schematic triple stage cascoded LNA using IDF technique. This configuration has been designed with the new technique and topology. In this stage, LNA has been designed using inductive feedback $\mathrm{L}_{16}, \mathrm{~L}_{26}$ and $\mathrm{L}_{36}$ at drain $\mathrm{M}_{2}, \mathrm{M}_{4}$ and $\mathrm{M}_{6}$ respectively. $\mathrm{L}_{10}$, $\mathrm{L}_{20}$ and $\mathrm{L}_{30}$ inductive generation source connected to the source of $\mathrm{M}_{1}, \mathrm{M}_{3}$ and $\mathrm{M}_{5}$. In addition, the $\mathrm{L}_{15}, \mathrm{~L}_{25}$ and $\mathrm{L}_{35}$ inductive $\mathrm{RF}$ choke placed between the source $\mathrm{M}_{2}$ to drain on the $\mathrm{M}_{1}, \mathrm{M}_{4}$ to drain $\mathrm{M}_{3}$ and $\mathrm{M}_{6}$ to drain on the $\mathrm{M}_{5}$. This topology also used the T-matching network at the input and output impedance 
(input impedance matching component at at $\mathrm{L}_{11}, \mathrm{~L}_{12}, \mathrm{C}_{11}, \mathrm{~L}_{21}, \mathrm{~L}_{22}, \mathrm{C}_{21} \mathrm{~L}_{31}, \mathrm{~L}_{32}, \mathrm{C}_{31}$ and output impedance matching component at $\mathrm{L}_{18}, \mathrm{~L}_{19}, \mathrm{C}_{12}, \mathrm{~L}_{28}, \mathrm{~L}_{29}$, $\mathrm{C}_{22}, \mathrm{~L}_{38}, \mathrm{~L}_{39}, \mathrm{C}_{32}$ ). By using Ansoft Designer SV, Smith Chart matching technique, the components of the amplifier are as shown in Table 4.

Table 4.Triple-Stage LNA Cascoded LNA Amplifier parameters

\begin{tabular}{|c|c|c|c|c|c|c|c|c|c|c|c|c|}
\hline & \multicolumn{12}{|c|}{ Components } \\
\hline $\begin{array}{l}1^{\text {st }} \text { Stage } \\
\text { LNA }\end{array}$ & $\mathrm{L}_{10}(\mathrm{nH})$ & $\mathrm{L}_{11}(\mathrm{nH})$ & $\mathrm{L}_{12}(\mathrm{nH})$ & $\mathrm{L}_{13}(\mathrm{nH})$ & $\mathrm{L}_{14}(\mathrm{nH})$ & $\mathrm{L}_{15}(\mathrm{nH})$ & $\mathrm{L}_{16}(\mathrm{nH})$ & $\mathrm{L}_{17}(\mathrm{nH})$ & $\mathrm{L}_{18}(\mathrm{nH})$ & $\mathrm{L}_{19}(\mathrm{nH})$ & $\mathrm{C}_{11}(\mathrm{pF})$ & $\mathrm{C}_{12}(\mathrm{pF})$ \\
\hline Value & 0.064 & 1.350 & 1.020 & 0.697 & 0.367 & 1.160 & 9.000 & 1.366 & 0.658 & 1.369 & 0.100 & 0.600 \\
\hline $\begin{array}{l}2^{\text {nd }} \text { Stage } \\
\text { LNA }\end{array}$ & $\mathrm{L}_{20}(\mathrm{nH})$ & $\mathrm{L}_{21}(\mathrm{nH})$ & $\mathrm{L}_{22}(\mathrm{nH})$ & $\mathrm{L}_{23}(\mathrm{nH})$ & $\mathrm{L}_{24}(\mathrm{nH})$ & $\mathrm{L}_{25}(\mathrm{nH})$ & $\mathrm{L}_{26}(\mathrm{nH})$ & $\mathrm{L}_{27}(\mathrm{nH})$ & $\mathrm{L}_{28}(\mathrm{nH})$ & $\mathrm{L}_{29}(\mathrm{nH})$ & $\mathrm{C}_{21}(\mathrm{pF})$ & $\mathrm{C}_{22}(\mathrm{pF})$ \\
\hline Value & 0.064 & 1.350 & 1.020 & 0.697 & 0.337 & 1.160 & 9.000 & 1.366 & 0.658 & 1.346 & 0.100 & 0.550 \\
\hline $\begin{array}{l}\text { Cascoded } \\
\text { LNA }\end{array}$ & $\mathrm{L}_{30}(\mathrm{nH})$ & $\mathrm{L}_{31}(\mathrm{nH})$ & $\mathrm{L}_{32}(\mathrm{nH})$ & $\mathrm{L}_{33}(\mathrm{nH})$ & $\mathrm{L}_{34}(\mathrm{nH})$ & $\mathrm{L}_{35}(\mathrm{nH})$ & $\mathrm{L}_{36}(\mathrm{nH})$ & $\mathrm{L}_{37}(\mathrm{nH})$ & $\mathrm{L}_{38}(\mathrm{nH})$ & $\mathrm{L}_{39}(\mathrm{nH})$ & $\mathrm{C}_{31}(\mathrm{pF})$ & $\mathrm{C}_{32}(\mathrm{pF})$ \\
\hline Value & 0.064 & 1.320 & 1.279 & 0.658 & 0.283 & 1.139 & 9.56 & 1.372 & 0.658 & 0.746 & 0.500 & 0.800 \\
\hline
\end{tabular}

From the architecture topology stated in the previous section, a triple stage cascoded LNA using IDF technique is designed to produce high gain, low noise figure, unconditional stability at specific bands and widen the bandwidth. However, this condition is strongly influenced by the passive components and topologies used at every stage LNA amplifiers. In this research, the proposed LNA is composed of three stages as shown in Figure. 6. LNA circuit used at each stage using the same topology consists of inductive drain feedback combined with inductive source degeneration, inductive RF choke placed between the two LNA amplifiers and the input and output ports using the T-matching network. Each stage is connected using the interstage matching $L_{B}$ and $C_{B}$.

The use of inductive drain feedback $\mathrm{L}_{16}$ for the first stage, $\mathrm{L}_{26}$ in the second stage and $\mathrm{L}_{36}$ in the third stage at the cascoded topology has produced high-gain, extended bandwidth, better stability and help in producing the best impedance at the input and output terminals. This is shown in Figure. 7 and Figure 8. In Figure 7, the change in the inductive $\mathrm{L}_{16}, \mathrm{~L}_{26}$ and $\mathrm{L}_{36}$ from $1 \mathrm{nH}$ to $10 \mathrm{nHvaries}$ the gain to increase significantly from $64 \mathrm{~dB}$ to $80 \mathrm{~dB}$ while the impedance matching at the input $\left(\mathrm{S}_{11}\right)$ and output terminals $\left(\mathrm{S}_{22}\right)$ are changes to good impedance from $-11 \mathrm{~dB}$ to $-13 \mathrm{~dB}$. While in Figure 8 , shown with the use of inductive drain feedback on the three stage have also resulted in the LNA amplifiers are unconditionally stability when changing the value of the three inductive from $1 \mathrm{nH}$ to $10 \mathrm{nH}$ has resulted in the stability of the meet at the same stability of 5.08. This will enable greater 
changes in bandwidth from $1.37 \mathrm{GHz}$ to $1.8 \mathrm{GHz}$. Adding the inductive drain feedback at the cascoded topology has provided high gain, wider bandwidth, better stability, higher reverse isolation and provide the best matching at the input or output terminal, that it also helps in increasing the bandwidth.

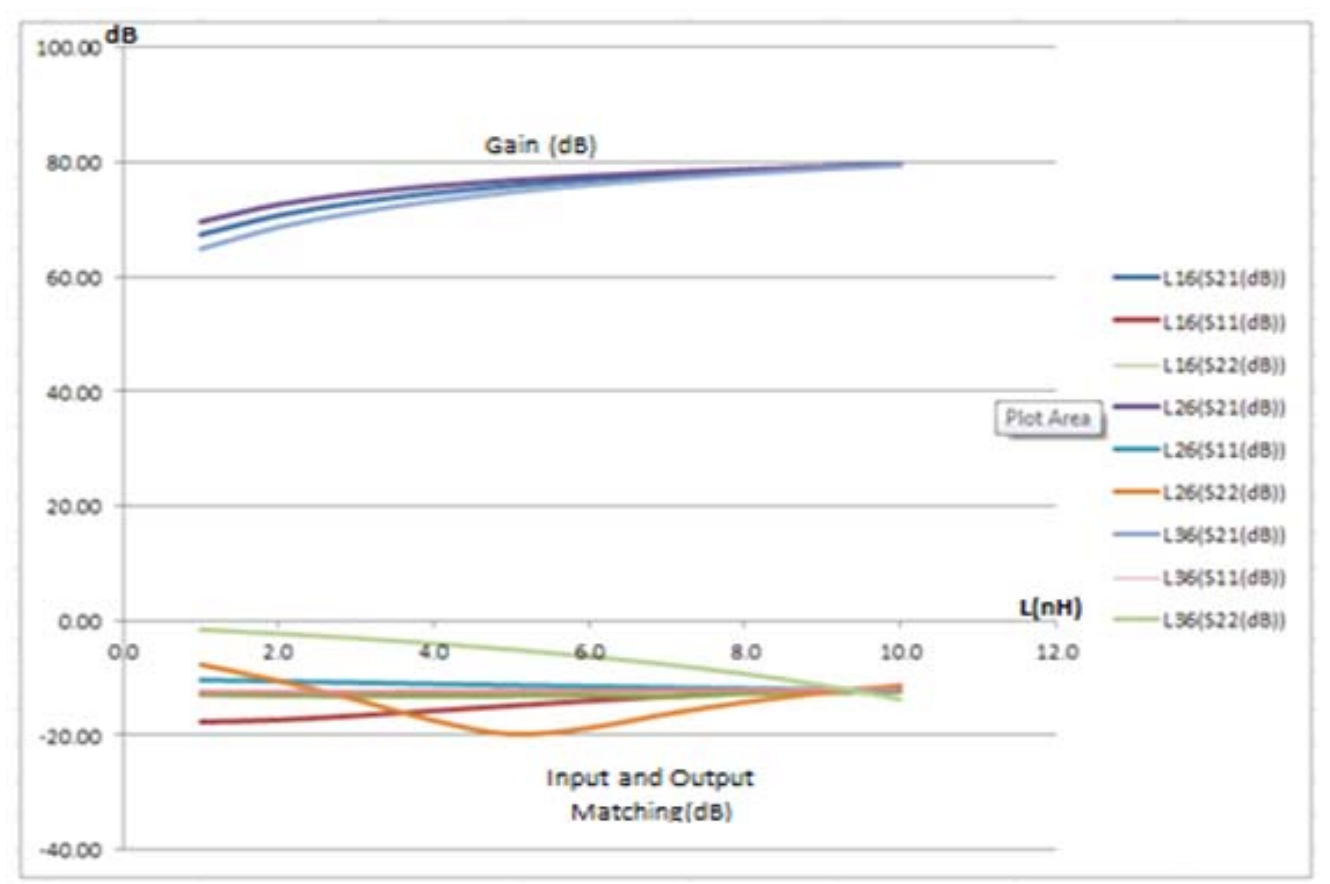

Figure 7. Affect changes value the $\mathrm{L}_{16}, \mathrm{~L}_{26}$ and $\mathrm{L}_{36}$ to the overall gain and matching impedance

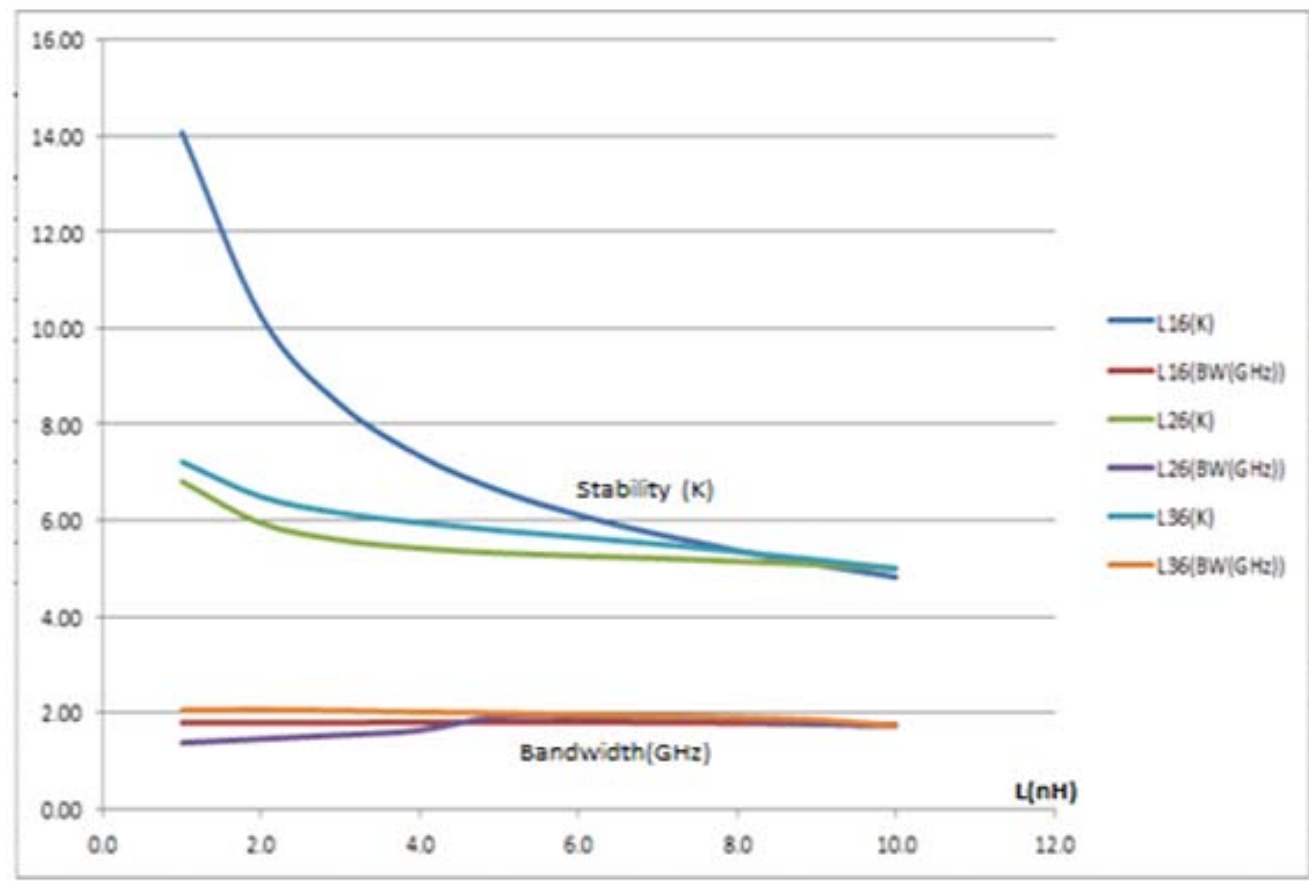

Figure 8. Affect changes value the $\mathrm{L}_{16}, \mathrm{~L}_{26}$ and $\mathrm{L}_{36}$ to the stability and bandwidth 


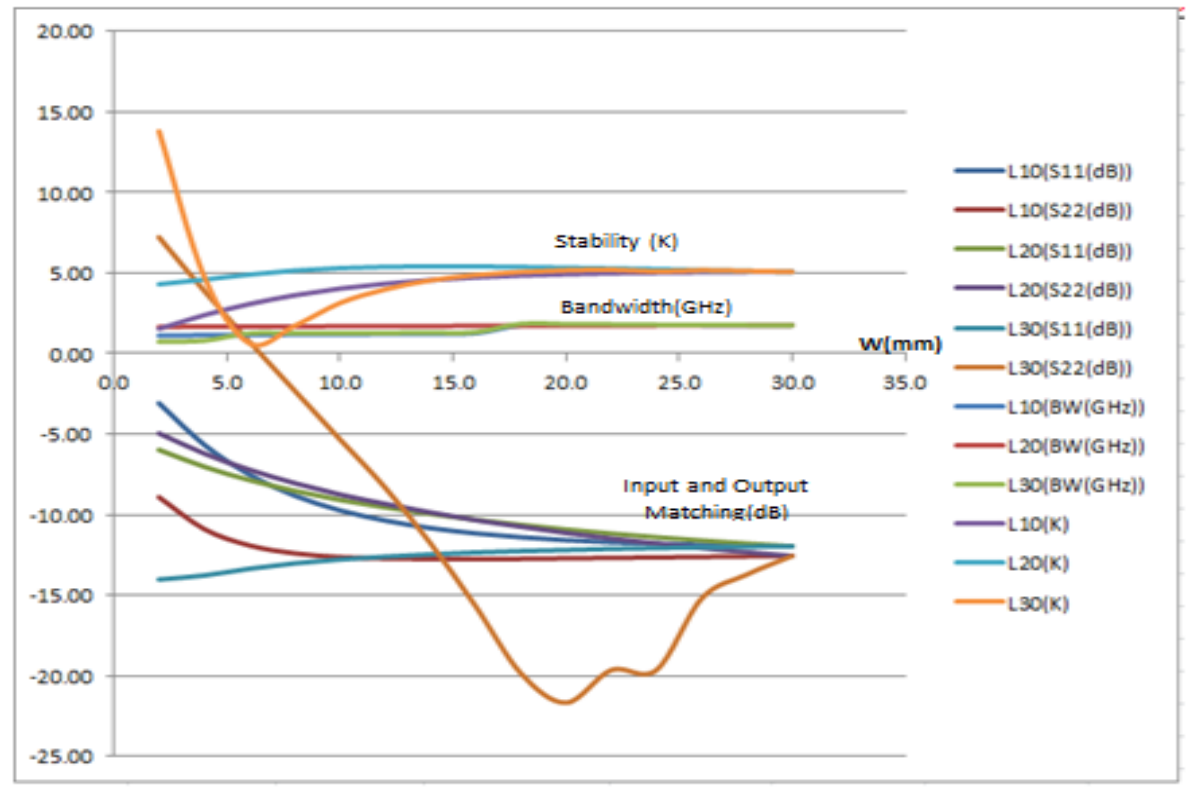

Figure 9. Affect changes value the $\mathrm{L}_{10}, \mathrm{~L}_{20}$ and $\mathrm{L}_{30}$ to the overall input -output matching, stability and bandwidth of the system

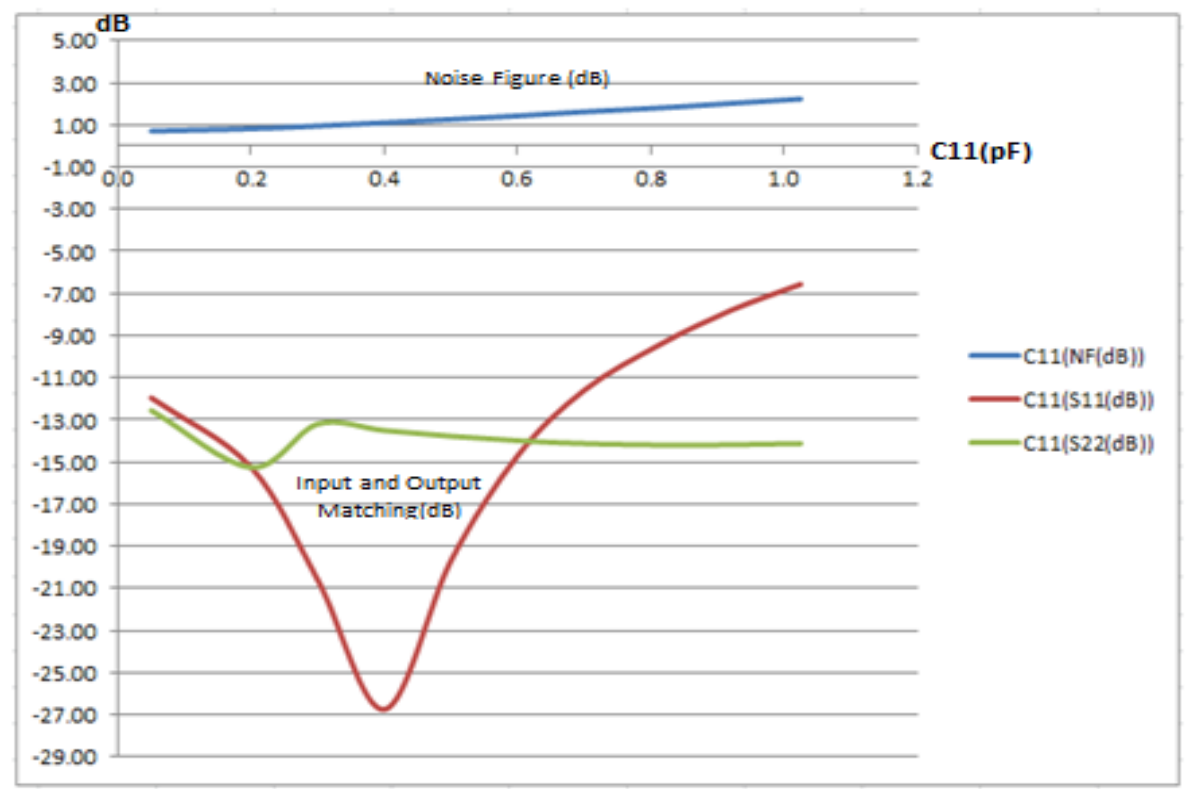

Figure 10. Affect changes value the $\mathrm{C}_{11}$ to the overall noise figure

In addition, the topology also uses an inductive source generation $\mathrm{L}_{10}, \mathrm{~L}_{20}$ and $\mathrm{L}_{30}$ in the three stage cascoded LNA has enabled designers to improve and control the impedance matching as shown in Figure 9. Whereas in the inductive source degeneration changed to a smaller value, which changes the $\mathrm{W}(\mathrm{mm})$ from $2 \mathrm{~mm}$ to $30 \mathrm{~mm}$ resulted in pure impedance occurs at the input and output matching and helps in getting the input and output of the optimal matching. This causes the input impedance $\left(\mathrm{S}_{11}\right)$ changes from $-3.08 \mathrm{~dB}$ to $-11.96 \mathrm{~dB}$. The output impedance $\left(\mathrm{S}_{22}\right)$ matching changes from $7.22 \mathrm{~dB}$ to $-12.56 \mathrm{~dB}$. These changes have 
improved input-output matching in LNA amplifiers capabilities and reducing the reflection loss at the circuit. When this condition occurs, it enhances the bandwidth and stability as shown in Figure 9.

The use of T-matching on this configuration also has helped reduce the reverse isolation and noise figure. Especially in the first stage cascoded LNA T-matching network at the input will control and determine the overall noise figure in the RF front-end receiver. This is shown in Figure 10 and Figure 11, where a change in the passive component values at $\mathrm{L}_{11}, \mathrm{~L}_{12}$ and $\mathrm{C}_{11}$ will affect the noise figure LNA amplifiers. At the T-matching in the second or third stage had no significant effect on the noise figure when the passive component in the $\mathrm{T}$ - matching altered.

In this case, we have chosen the value of $\mathrm{C}_{11}$ from $0.1 \mathrm{pF}$ up $1 \mathrm{pF}$ causing noise figure varies from $0.71 \mathrm{~dB}$ to $2.23 \mathrm{~dB}$. However, the LNA specifications amplifiers to be built require the $S_{11}$ be smaller than $10 \mathrm{~dB}$ a trade-off needs to be done. A value component $\mathrm{C}_{11}$ between $0.1 \mathrm{pF}$ will be chosen. Where it has, been producing noise figure LNA receiver to $0.71 \mathrm{~dB}$.In addition, passive inductive component $\mathrm{L}_{11}$ and $\mathrm{L}_{12}$ also have a significant impact on noise figure to the overall system. Where changes in the value of microstrip $\mathrm{L}_{11}$ and $\mathrm{L}_{12}$ from $1 \mathrm{~mm}$ to $7 \mathrm{~mm}$ has resulted in the noise figure, changed from $0.76 \mathrm{~dB}$ to $0.71 \mathrm{~dB}$ and $0.66 \mathrm{~dB}$ to $0.71 \mathrm{~dB}$ respectively. Then the noise figure willincrease back if the inductive $\mathrm{L}_{11}$ extends beyond $7 \mathrm{~mm}$. This can be demonstrated by Figure 11 .

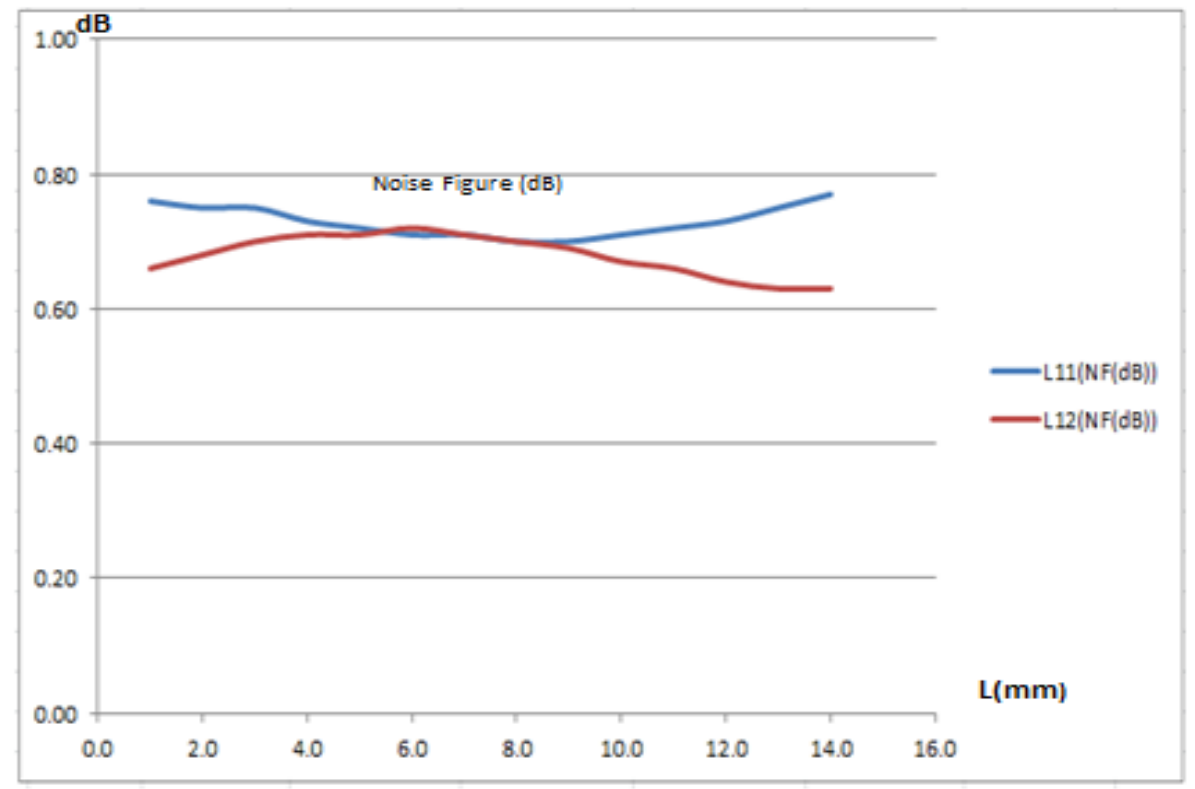

Figure 11. Affect changes value the $\mathrm{L}_{11}$ and $\mathrm{L}_{12}$ to the overall noise figure

\section{Results}

This section demonstrates the measurement resultfor triple stages cascoded LNA with inductive drain feedback used at a frequency of $5.8 \mathrm{GHz}$.It is implemented in a SuperHEMT technology. The design based on the topology shown in Figure 6 . Table 5 shows the summary of the measured performance and comparison for different topologies of the LNA amplifier for researchers at recently reported.The recorded result plot for gain $S_{21}$, input reflection loss $S_{11}$, output reflection loss $S_{22}$ and return loss $S_{12}$ of the LNA are shown in Figure 12 (a). While at Figure 12 (b) and 12 (c) shows noise figure and stability of the triple cascoded LNA amplifier. At the Figure 12 (a), the input reflection $\mathrm{S}_{11}$ is $-11.96 \mathrm{~dB}$ while the output reflection $\mathrm{S}_{22}$ is $-12.56 \mathrm{~dB}$. Acquisition of $\mathrm{S}_{11}$ and $\mathrm{S}_{22}$ is less than $-10 \mathrm{~dB}$ can produce the best impedance matching, which shows the effectiveness of using inductive degeneration and T-matching 
network at the LNA amplifier circuit. In addition, as shown in Figure 12 (a), use of cascoded topology with inductive drain feedback has resulted in transfer forward gain $S_{21}$ reaches 79.16 $\mathrm{dB}$ at $5.8 \mathrm{GHz}$. The return loss $\mathrm{S}_{12}$ (reverse isolation) gives a very low value to $-100.22 \mathrm{~dB}$.

The low values $\mathrm{S}_{12}$ have provided advantages in reducing LO leakage substantially which arises from capacitive paths and substrate coupling. In Figure. 12 (b) overall noise figure (NF) is $0.71 \mathrm{~dB}$, which is the best result reported among the published LNAs in SuperHEMT and $0.18 \mu \mathrm{m}$ technology especially in the high frequency band.The stability $\mathrm{K}$ is 5.8 as shown in Figure 12 (c). . The value of stability obtained is greater than 1, and the LNA amplifiers are currently in a state of unconditionally stable.From Figure 12 (a), it is observed that, the $3 \mathrm{~dB}$ bandwidth of around $1.76 \mathrm{GHz}$ was obtained and thus complies with the targeted result of more than $1 \mathrm{GHz}$. All the result values are within the design specification, as stated in Table 2.

Table 5. Comparison performance summary of the different topology of the LNA amplifier: published and this work

\begin{tabular}{|c|c|c|c|c|c|c|c|c|c|}
\hline References & Topology & Technology & $\begin{array}{c}\text { Input } \\
\text { Reflection } \\
\mathrm{S}_{11} \mathrm{~dB}\end{array}$ & $\begin{array}{c}\text { Output } \\
\text { Reflection } \\
\mathrm{S}_{22} \mathrm{~dB}\end{array}$ & $\begin{array}{c}\text { Forwar } \\
\text { d } \\
\text { Transfe } \\
\text { r } S_{21} \\
\text { dB }\end{array}$ & $\begin{array}{c}\text { Retur } \\
n \\
\text { Loss } \\
S_{12} \mathrm{~dB}\end{array}$ & $\begin{array}{l}\text { NF } \\
\text { dB }\end{array}$ & $\begin{array}{l}\text { BW } \\
\text { GHz }\end{array}$ & $\begin{array}{c}\text { Stability } \\
\text { (K) }\end{array}$ \\
\hline [12] & $\begin{array}{l}\text { Cascode } \\
\text { Feedback }\end{array}$ & $\begin{array}{l}0.18-\mu \mathrm{m} \\
\text { CMOS }\end{array}$ & $<-7.8$ & $<-10$ & 11.9 & $<-40$ & $\begin{array}{l}4.1- \\
4.6\end{array}$ & $2-6.5$ & - \\
\hline [17] & $\begin{array}{c}2 \text { stage } \\
\text { LNA with } \\
\text { reactive } \\
\text { feedback }\end{array}$ & $\begin{array}{c}0.13-\mu \mathrm{m} \\
\text { CMOS }\end{array}$ & $<-9.9$ & - & 15.3 & -34 & 2.5 & $\begin{array}{l}3.1- \\
10.6\end{array}$ & - \\
\hline [18] & $\begin{array}{c}\text { CS and } \\
\text { CG with } \\
\text { Parallel- } \\
\text { to-Series } \\
\text { Resonant } \\
\text { Matching } \\
\text { Network }\end{array}$ & $\begin{array}{c}\text { TSMC } 0.18- \\
\mu \mathrm{m}\end{array}$ & $<-9$ & $<-8$ & $9.6-12.7$ & $<-45$ & $\begin{array}{l}2.5- \\
3.9\end{array}$ & $4-9$ & - \\
\hline [19] & $\begin{array}{c}\text { Cascaded } \\
\text { LNA + } \\
\text { RFA }\end{array}$ & $\begin{array}{c}\text { SuperPHEM } \\
\mathrm{T}\end{array}$ & -11.4 & -12.4 & 52.4 & -39.1 & 1.3 & 1.125 & - \\
\hline [22] & $\begin{array}{c}2 \text { stage } \\
\text { CS-CG } \\
\text { with } \\
\text { source } \\
\text { inductive } \\
\text { degenerati } \\
\text { on }\end{array}$ & $\begin{array}{c}0.18-\mu \mathrm{m} \\
\text { CMOS }\end{array}$ & $<-12.2$ & - & 26.25 & - & 2.2 & 0.4 & 20 \\
\hline [20] & $\begin{array}{c}\text { LNA } \\
\text { using } \\
\text { Drain- } \\
\text { Fully- } \\
\text { Differentia } \\
1 \text { Active } \\
\text { Inductive } \\
\text { Gain- } \\
\text { peaking }\end{array}$ & $\begin{array}{l}0.18-\mu \mathrm{m} \\
\text { CMOS }\end{array}$ & $<-7$ & $<-20$ & 17.34 & -21.2 & 2.5 & 2 & - \\
\hline [21] & $\begin{array}{c}\text { LNA } \\
\text { shunt } \\
\text { feedback }\end{array}$ & $\begin{array}{l}180 \mathrm{~nm} \\
\text { CMOS }\end{array}$ & $<-11.2$ & $<-22.8$ & 19.9 & -32.5 & 2.63 & 0.2 & 2.5 \\
\hline $\begin{array}{l}\text { [This } \\
\text { Work] }\end{array}$ & $\begin{array}{c}\text { Triple } \\
\text { cascoded } \\
\text { LNA } \\
\text { using } \\
\text { inductive } \\
\text { drain } \\
\text { feedback }\end{array}$ & $\begin{array}{c}\text { SuperPHE } \\
\text { MT }\end{array}$ & -11.96 & -12.56 & 79.16 & 100.22 & 0.71 & 1.76 & 5.08 \\
\hline
\end{tabular}

Note: (-) - not stated 
Kamil PONGOT, et al

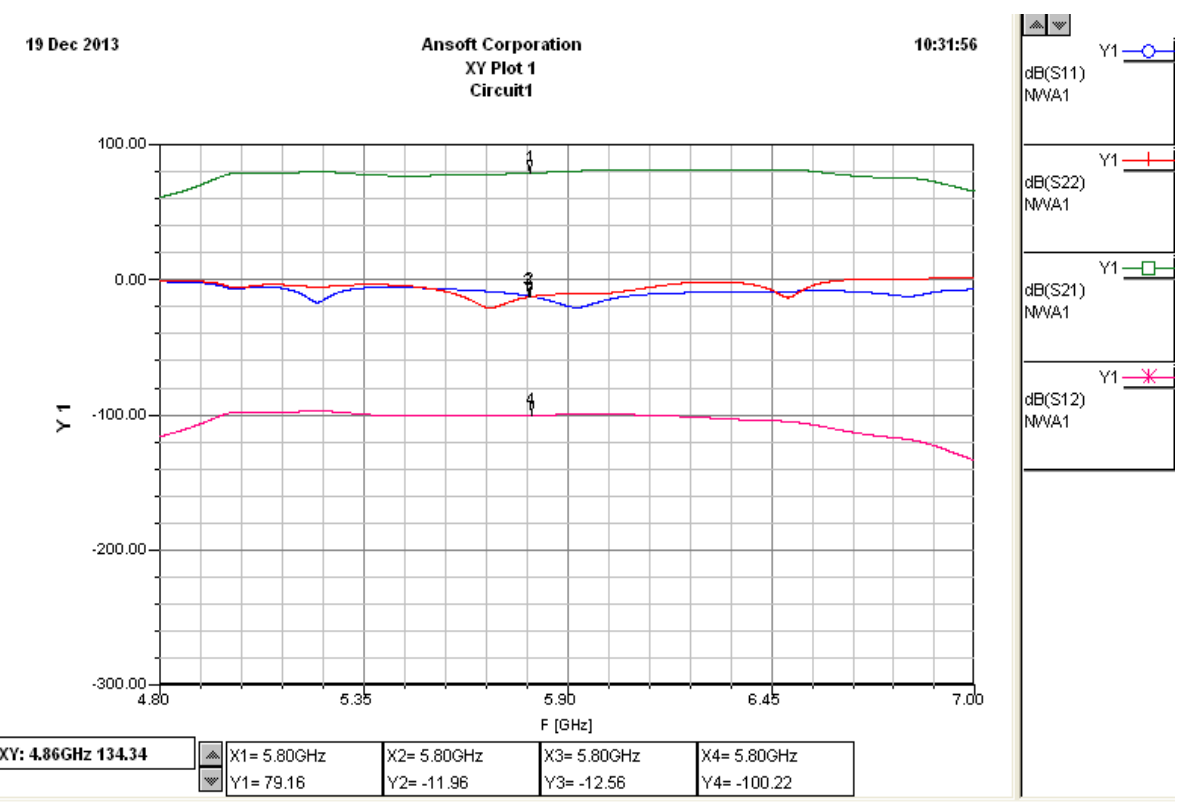

Figure 12 (a). S-parameter for Triple Stages Cascoded LNA

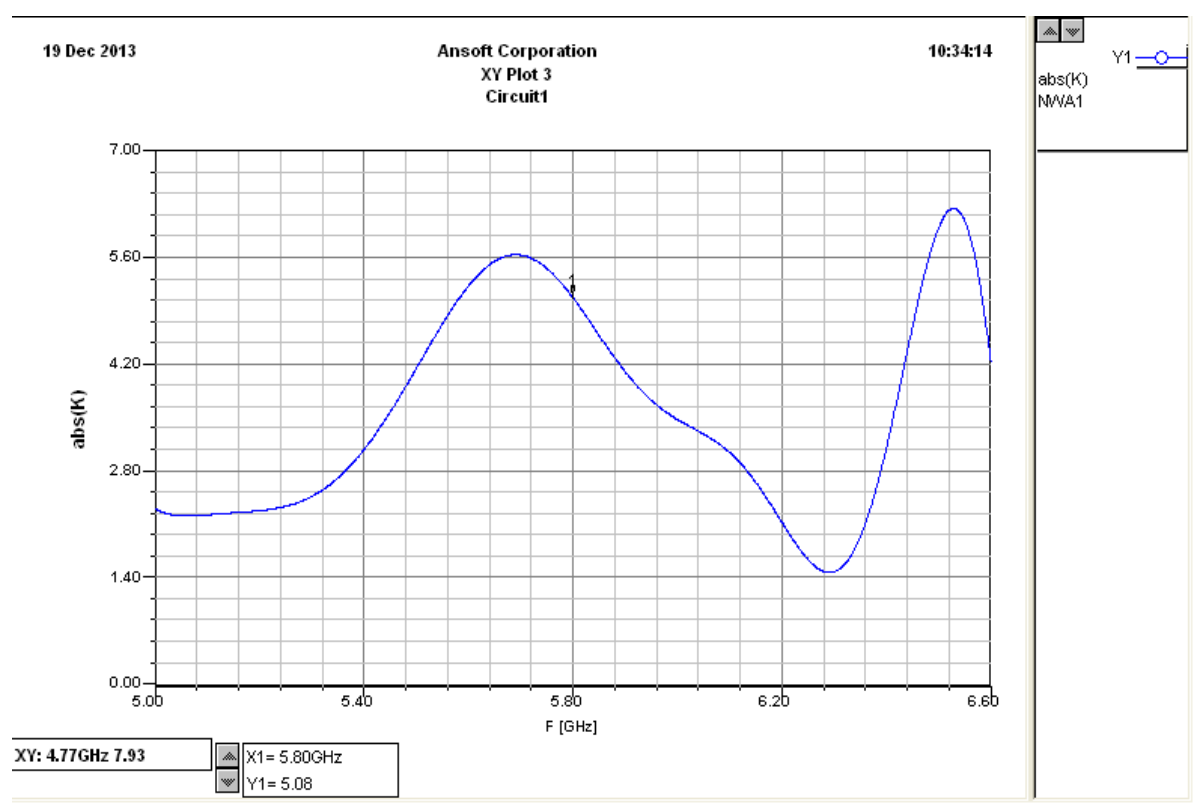

Figure 12 (b). Noise Figure for Triple Stages Cascoded LNA 


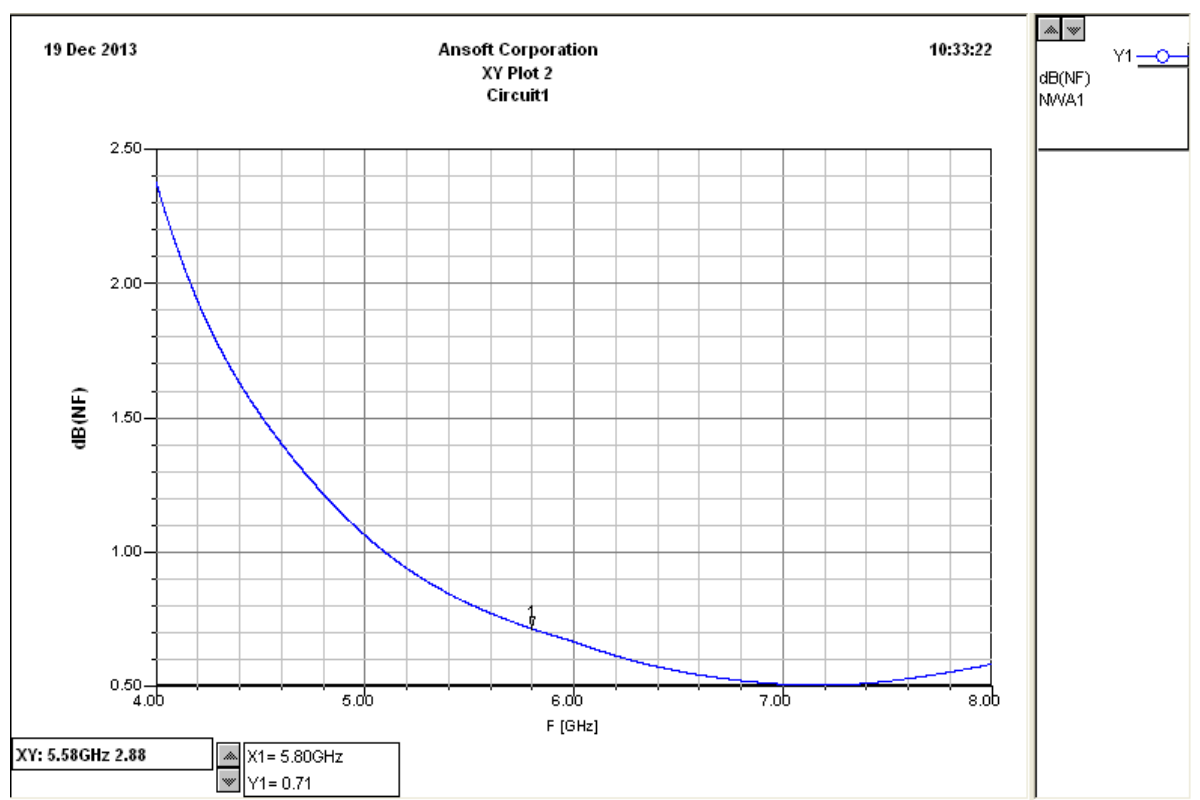

Figure 12 (c). Stability for Triple Stages Cascoded LNA

\section{Conclusions}

The feasibility of a newly proposed triple stage cascoded LNA by using inductive feedback technique, inductive source generation, T-matching and inductive RF choke for improving noise performance, achieving good input matching, wider the bandwidth and high power gain have been demonstrated in this paper. The circuit consisted of three stages, whereby design issues of noise, gain, stability and bandwidth were almost separated into each stage; the first stage contributed to reduce the noise figure and the second stage to improve the LNA's stability and the third stage to control the bandwidth. While inductive drain feedback at each stage will control and improve the gain. The proposed LNA provides the gain $\left(\mathrm{S}_{21}\right)$ was 79.16 $\mathrm{dB}$, and the 3-dB bandwidth was $1.76 \mathrm{GHz}$. LNA performance can be further enhanced by strengthening input and output impedance matching of the return loss $\left(\mathrm{S}_{12}\right)$, output reflection loss $\left(\mathrm{S}_{22}\right)$ and input reflection loss $\left(\mathrm{S}_{11}\right)$ of the respective value are $-100.22 \mathrm{~dB},-12.56 \mathrm{~dB}$ and -11.96 dB.Recorded result for stability and noise figure (NF) cascoded LNA amplifier observed provide 5.08 and $0.71 \mathrm{~dB}$ respectively. In conclusion, , it has been demonstrated that by applying a triple stage cascoded LNA amplifier, a minimum noise figure, higher gain, and wider the bandwidth which is the best measurement reported among the published WiMAX LNAs.

\section{Acknowledgment}

The work described in this paper was fully supported bythe CentreFor Research And Innovation Management (CRIM), Universiti Teknikal Malaysia Melaka (UTeM). Melaka, Malaysia, under research grant PJP/2013/FKEKK (11C)/S01182.

\section{References}

[1]. C. Smith and J. Meyer, 2004. 3G Wireless with WiMAX and WiFi: 802.16 and 802.11, New York: McGraw-Hill.

[2]. IEEE 802.16-2004, 2004. IEEE standard for local and metropolitan area networks: Air interface for fixed broadband wireless access systems.

[3]. Othman A. R, Hamidon A. H, Abdul Wasli. C, Ting J. T. H, Mustaffa M.F, Ibrahim A.B, 2010. Low Noise, High Gain RF Front End Receiver at $5.8 \mathrm{GHz}$ for WiMAX Application. Journal of Telecommunication and Computer Engineering. 
[4]. IEEE P802.16Rev2/D2, 2007 "DRAFT Standard for Local and metropolitan area networks, Part 16: Air Interface for Broadband Wireless Access Systems,”, pp. 2094.

[5]. A. R. Othman, A B. Ibrahim, M. N. Husain, A. H. Hamidon, and Jsam Hamidon, 2012. Low Noise Figure of Cascaded LNA at $5.8 \mathrm{GHz}$ Using T-Matching Network for WiMAX Applications. International Journal of Innovation, Management and Technology, Vol. 3, No. 6.

[6]. Sudip Shekhar, Jeffery S. Walling, Sankaran Aniruddhan and David J. Allstot, 2008. CMOS VCO and LNA using tuned-input tuned-output circuits. IEEE Journal of SolidState Circuits, vol. 43, no. 5, pp.1177-1186.

[7]. L. Belostotski and J. W. Haslett,2006. Noise figure optimization of inductively degenerated CMOS LNAs with integrated gate inductors. IEEE Trans. Circuits Syst. I: Reg. Papers, vol. 53, no. 7, pp. 1409-1422.

[8]. Tamer Ragheb, Arthur Nieuwoudt, and Yehia Massoud, 2006 . Modeling of 3.1-10.6 GHz CMOS filter-based Low noise amplifier for ultra-wideband receivers. In Proceedings of the IEEE Annual Wireless and Microwave Technology Conference (WAMICON 20'06), pp. $1-5$

[9]. Chang, J.F. and Y.S. Lin, 2011. 0.99 MW 3-10 GHz Common-Gate CMOS UWB LNA using t-match input network and self-body-bias technique. Elect. Lett., 47: 658-659.

[10]. W. Zhuo, X. Li, S. Shekhar, S. H. K. Embabi, J. Pineda de Gyvez, D. J. Allstot, and E. Sánchez-Sinencio, 2005. A capacitor cross-coupled common-gate low noise amplifier. IEEE Transaction on Circuits and Systems II: Express Briefs, vol. 52, no. 12, pp. 875879.

[11]. Hyejeong Song, Huijung Kim, Kichon Han, Jinsung Choi, Changjoon Park, and Bumman Kim, "A sub-2dB NF dual-band CMOS LNA for CDMA/WCDMA applications," IEEE Microwave and WirelessComponents Letters, vol. 18, no. 3, pp. 212-214.2008.

[12]. Jihak Jung; Kyungho Chung; Taeyeoul Yun; Jaehoon Choi; Hoontae Kim, 2006. Ultrawideband low noise amplifier using a cascode feedbacktopology. Silicon Monolithic Integrated Circuits in RF Systems,Digest of Papers. vol., no., pp.4.

[13]. Bevin G. Perumana1, Jing-Hong C. Zhan1, Stewart S. Taylor1, Brent R. Carlton1, and Joy Laskar, 2008. A 9.2 mW, 4-8 GHz resistive feedback CMOS LNA with $24.4 \mathrm{~dB}$ gain, $2 \mathrm{~dB}$ noise figure, and $21.5 \mathrm{dBm}$ output IP3. In Proceedings of the IEEE Topical Meeting on Silicon Monolithic Integrated Circuits in RF Systems (SiRF 2008), pp. 206-209.

[14]. Abu Bakar Ibrahim, Abdul Rani Othman, Mohd Nor Husain, and Mohammad Syahrir Johal, 2011. Low Noise, High Gain LNA at $5.8 \mathrm{GHz}$ with Cascode and Cascaded Techniques Using T-Matching Network for Wireless Applications. International Journal of Information and Electronics Engineering, Vol. 1, No. 2.

[15]. M. Pozar, David. Microwave and RF Wireless System, 2001. Third Avenue, N. Y. John Wiley \& Sons.

[16]. Leon, Michael Angelo G. Lorenzo and Maria Theresa G.De., 2010. Comparison of LNA Topology for Wimax Application in a Standard 90-nm CMOS Process. 12th International Conference on Computer Modelling and Simulation.pp-642-647.

[17]. Reiha, M.T.; Long, J.R.; Pekarik, J.J., 2006. A 1.2 V reactive-feedback 3.1-10.6 GHz ultrawideband low-noise amplifier in 0.13 /spl mu/m CMOS. Radio Frequency Integrated Circuits (RFIC) Symposium, 2006 IEEE , vol., no., pp.4 pp.,, 11-13 .

[18]. Yu-Tsung Lo; Jean-Fu Kiang, 2011. Design of Wideband LNAs Using Parallel-to-Series Resonant Matching Network Between Common-Gate andCommon-Source Stages. Microwave Theory and Techniques, IEEE Transactions on, vol.59, no.9, pp.2285,2294.

[19]. Abu Bakar Ibrahim, Abdul Rani Othman, Mohd Nor Husain, Mohammad Syahrir Johal, J. Sam Hamidon, 2012. The Cascode LNA with RFAmplifier at $5.8 \mathrm{GHz}$ Using TMatching Network for WiMAX Applications. Journal of Telecommunication and Computer Engineering. 
[20]. ShimaAlizadehZanjani, Marzie Moradi, Roshanak Zabihi, Pooya Torkzadeh, 2012 . A Gain Flattened LNA by using Drain-Fully-DifferentialActive Inductive Gain Peaking Technique. International Journal of Computer Applications in Engineering Sciences.Vol II, Issue III, September 2012.

[21]. Kavyashree.P, Dr. Siva S Yellampalli, 2013. The Design of Low Noise Amplifiers in Nanometer Technology for WiMAX Applications. International Journal of Scientific and Research Publications, Vol 3, Issue 10, October 2013.

[22]. Gh.R. Karimi, S. Babaei Sedaghat, 2012. Ultra low voltage, ultra low power low noise amplifier for $2 \mathrm{GHz}$ applications. International Journal ofElectronics and Communications. ), Issue 66, pp. 18-22.

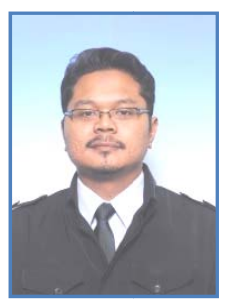

Kamil PONGOT was born in Johor in 1977. He received the Dip. Eng and B. Eng. Degree in Electrical Telecommunication Engineering from University Technology of Malaysia in 1998 and 2000 respectively. He received the M. Sc Degree in Electronic and Computer Engineering from Hanyang University in 2009. From 2000 to 2002, he was with STMicroelectronics, based in Malaysia where he worked as Testing Engineer. He worked as a Lecturer at MARA Technical College. Currently is working toward the Ph.D. degree in new RF front end receiver architecture for WiMAX/Wireless Application at the University Teknikal Malaysia Melaka.

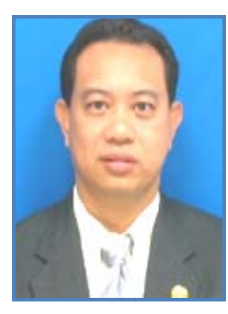

Abdul Rani OTHMAN was born in Kedah in 1964. He received B. Eng (Hons) in Electrical and Electronic from University of Strathclyde Scotland and Master Degree in Electrical and Electronic from University Technology of Malaysia in 1987 and 1989 respectively. He received Ph.D in RF frontend receiver for wireless application from University of Teknikal Malaysia Melaka in 2010 . He is currently a Associate Professor and also Dean at the Faculty of Electronic and Computer Engineering, University Teknikal Malaysia Melaka. His research interests include a variety of RF communication design and microwave application. He also investigates radiowave propagation in wireless communication systems.

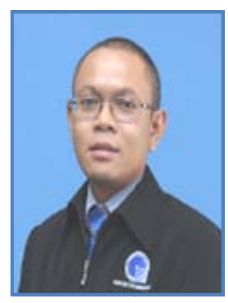

Zahriladha ZAKARIA - was born in Malaysia in 1975. He received the B. Eng. and M. Eng. in Electrical and Electronic Engineering from the Universiti Teknologi Malaysia in 1998 and 2004 respectively. He obtained his Doctorate from The University of Leeds in 2010 in the area of Microwave Engineering. From 1998 to 2002, he was with STMicroelectronics, based in Malaysia where he worked as a Product Engineer. He is currently a Senior Lecturer and also the Deputy Dean (Academic) at the Faculty of Electronic and Computer Engineering, University Teknikal Malaysia Melaka, where he teaches electronic system, communication principles, microwave engineering, and signal processing. His research interests include a variety of microwave device development such as planar and non-planar microwave filters, amplifiers and antennas. He also investigates radiowave propagation in wireless communication systems. 


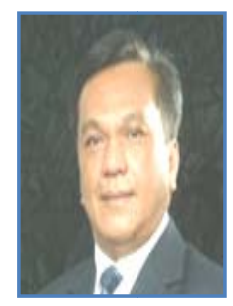

Mohamad Kadim SUAIDI - was born in Sarawak in 1960. He received the BSc (Hons) in Applied Physics and Electronic and Master of Science. In Microwave Engineering from the Portsmouth University, U.K in 1983 and 1984 respectively. He obtained his Doctor of Philosophy University of Technology Loughborough, U.K in 1991 in the area of Optoelectronics Engineering. From 2012 to 2013 he was Deputy Vice Chancellor (Academic \&International ) at University Teknikal Malaysia Melaka He is currently a Vice Chancellor at the University Malaysia Sarawak. His research interests include a variety of microwave device development such as planar and non-planar microwave filters, amplifier, antennas, Optoelectronic, laser and sensor system. He also investigates radiowave propagation in wireless communication systems.

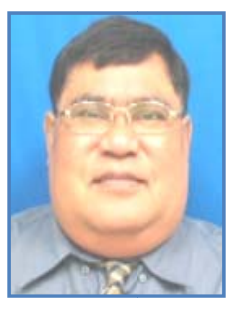

Abdul Hamid HAMIDON was born in Penang in 1950. He received the B. Eng.. Electrical from Monash University Australia in 1976 and M. Sc degree in Electronics from University of Wales. He is currently a Senior lecturer and Professor at the Faculty of Electronic and Computer Engineering, University Teknikal Malaysia Melaka, where he teaches electronic system, communication principles, microwave engineering, and Embedded system. His research interests include Industrial Electronics, Analog Electronics, RF Subsystems, Instrumentation.

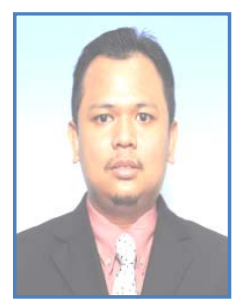

Azman AHMAD was born in Penang in 1979. He received the B. Eng. Degree in Electrical (Electronic) Engineering from University Technology of Malaysia in 2002. He received the Master Degree in Electronic (Electronic System) Engineering from University Teknikal Malaysia Melaka in 2013. From 2002 to 2008, he was with Sony EMCS Sdn Bhd, based in Malaysia where he worked as Senior Product Engineer. He worked as a Lecturer at MARA Technical College. Currently is working toward the Ph.D. degree in new RF front end receiver architecture for LTE Application at the University Teknikal Malaysia Melaka

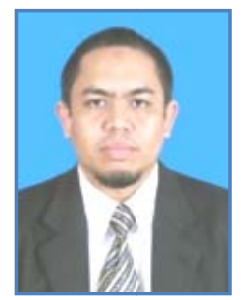

Mohamad Tarmizy AHMAD was born in Penang in 1973. He is a $\mathrm{PhD}$ student Faculty of Electronics and Computer Engineering, University Teknikal Malaysia, Melaka (UTEM). He received his bachelor degree of Electrical Engineering in 1997 and master degree in Technical Education in 1998 from University Technology of Malaysia. He worked as a lecturer at Seberang Perai Polytechnic, Penang. He started his PhD from November 2013 exploring of field microwave radar and imaging system. 